\title{
Provesicular Based Colloidal Carriers for Transdermal Drug Delivery: Formulation Aspects and Bioavailability Enhancement of Acyclovir Proliposomal Gels
}

\author{
Mateti Ashok ${ }^{1, *}$, Mohammed Habibuddin'2, Jukanti Raju ${ }^{3}$ \\ 'Department of Pharmaceutics, Trinity College of Pharmaceutical Sciences, Peddapalli, Telangana, INDIA. \\ 2Department of Pharmaceutics, Tou Pharma bio Pvt. Ltd., Hyderabad, Telangana, INDIA. \\ ${ }^{3}$ Department of Pharmaceutics, Drugs Inspector, Hyderabad, Telangana, INDIA.
}

\begin{abstract}
Background: Acyclovir (ACV) a 21-deoxy guanosine analogue effective against Herpes Simplex Virus (both type 1 and 2 ) and other viral diseases, mainly acts by inhibiting the viral DNA polymerase. The limited oral bioavailability of ACV (5-10\%) requires higher dosage (400-800 mg), results in neurotoxicity and renal failure. Topically, the lower efficacy of ACV is attributed to inadequate drug permeation across the stratum corneum (SC). Methods: In present research, ACV containing proliposomes formulated using various ratios of lipid mixtures (Phosphotidyl choline and Cholesterol) by co acervation phase separation method. Results: The formulated vesicles are having the acceptable particle size range $(385-616 \mathrm{~nm})$. Other characters like morphological behaviour, zeta potential, polydispersity index and entrapment efficiency were evaluated. In vitro release studies reveal the controlled delivery of ACV from formed liposomes. Significant higher permeation parameter values [flux (Jss), permeability coefficient $(\mathrm{Kp})$ and enhancement ratio (ER)] evaluated from all the formulations by
\end{abstract}

performing ex vivo permeation studies using male wistar rats. 3.24 fold increment was observed in bioavailability of optimized formulation than control (oral suspension). The formulated ACV proliposomal gels were more stable when stored at $4^{\circ} \mathrm{C}$. Conclusion: Improved bioavailability of ACV incorporated proliposomal gels than control reveals its potential in releasing of drug applied through transdermal route.

Key words: Proliposomes, Acyclovir, Transdermal, Permeation, Flux, Enhancement Ratio.

Correspondence

Mr. Mateti Ashok

Department of Pharmaceutics, Trinity College of Pharmaceutical Sciences, Peddapalli, Telangana, INDIA.

Email: matetiashok2301@gmail.com

DOI: $10.5530 /$ ijpi.2021.2.35

\section{INTRODUCTION}

Transdermal drug delivery system serves as a surrogate for oral route of administration avoiding of first pass metabolism, offers many advantages like easy of drug administration and termination of action makes the transdermal route of drug delivery more attractive. ${ }^{1}$ Stratum corneum (SC) is the main obstacle in transdermal delivery which acts as the rate limiting step for drug absorption across the skin. One of the promising delivery strategy to improve the transdermal delivery include the use of colloidal vesicular carriers like liposomes, niosomes, ethosomes, transferosomes and elastic liposomes etc. ${ }^{2-6}$ Among them the liposomes have gained much interest and were lucrative. In spite of many advantages the success rate of liposomes was not to the mark which can be attributed to many drawbacks like aggregation, sedimentation and phospholipid hydrolysis and oxidation. The proliposomal systems tactic has provided a major breakthrough in resolving the stability issues pertaining to the vesicular dispersions. ${ }^{7}$

The mechanisms underlying for enhancement in permeation from vesicular systems include a) the vesicles in contact with SC can fuse and provide a better contact with skin surface leading to higher vesicleskin interactions b) the intercalation of vesicles into the intercellular lipid layers of the skin may also lead to disorganization of the regular structure of the skin with altered permeability characteristics of SC thus impede the barrier function. However the size and composition of vesicles, nature of drug and biophysical factors are the important factors to be taken into consideration which contribute for efficient vesicle-skin interaction. Liposomes are the most promising and highly researched novel drug delivery systems however they suffer from several stability problems such as aggregation, susceptibility to hydrolysis and oxidation. These stability problems can be avoided by formulating these vesicular carriers into Proliposome systems. ${ }^{8}$

Proliposomal gels comprises of drug, lipid surfactant portion with minimum quantities of ethanol and water. The formulations upon application onto the surface of skin get hydrated with water from skin under occlusion and renovate into liposomes which favour the drug delivery via the Stratum Corneum. ${ }^{9,10}$

Acyclovir (ACV) acts by inhibiting Herpes virus DNA replication and is used in effective management of cutaneous infections due to Herpes group (Herpes Simplex virus type 1 and 2) that occurs at the basal epidermis. ${ }^{11}$ The current modes of treatment for Herpes group infections include administering ACV either orally or topically as ointment or creams. However, the limited oral bioavaliability (5-10\%) makes its clinical application greatly restricted and high systemic exposure is required in order to get the desired AVC levels in the systemic circulation. The reports clearly indicate that the efficiency of topical ACV preparations also limited and controversial due to the low penetrations of the free drug to the target site that is basal epidermis. ${ }^{12,13}$ Earlier several attempts were made to improve the transcutaneous permeation of ACV by using specialized techniques and/or delivery systems like iontophoresis, ${ }^{14,15}$ microdialysis, ${ }^{16}$ ion-exchange membrane assisted iontophoresis, ${ }^{17}$ elastic 
liposomes ${ }^{18}$ etc. Since the degree of permeation not only depends on the physicochemical characteristics of the drug, but also on the type of vesicle.

Aqueous liposomal suspensions undergo sedimentation, hydrolysis of phospholipids chasten stability circumscribe its shelf life. Formulation of proliposomes is an amenable approach to ameliorate these problems. The Mechanism of budding off and pinching out of liposomes from proliposomal bilayer involves addition of water followed by agitation ruptures the bilayer resulting in formation of small size vesicles. Phospholipids act as surfactants, causes fluidization of stratum corneum (SC) by interacting with SC lipids. Individual molecules of phospholipids shows negligible effect, but self assembled structures of phospholipids generate micelle or vesicle which fuse, disrupt the SC lipid bilayer thereby permeation enhancement achieved.

In present study, soya phosphotidyl choline (SPC) preferred than egg phosphotidyl choline (EPC). SPC contains hydrophobic unsaturated fatty acids such as oleic acid and linoleic acid which have permeation enhancement property, whereas EPC contains only saturated fatty acids restricts permeation enhancement. ${ }^{19,20}$ Due to intrinsic composition SPC gives larger vesicles than EPC. Nevertheless, SPC efficiently arrests crystalline compact transition point to produce crystalline proliposomal gel than EPC. ${ }^{21}$ Cholesterol acts as vesicular cement forms a thin film surrounding the vesicle. It intercalates with bilayer, increases the microviscosity and rigidity of vesicle there by prevents drug leakage leads to improved entrapment efficiency.

In present research, proliposomes containing ACV developed using various molar ratios of SPC and cholesterol. Flux, permeability coefficient enhancement ratio(ER) estimated across excised rat skin using Franz diffusion cell. Pharmacokinetic studies were conducted in male wistar rats for the assessment of ACV bioavaliability across the skin via optimized ACVPL gel.

\section{MATERIALS AND METHODS}

\section{Materials}

Acyclovir was a kind gift sample from Finoso Pharma, Hyderabad, India. Soya Phosphotidyl Choline (Phospholipon 90G) was generously donated by Lipoid, Germany. Cholesterol was obtained from E merck, Mumbai, India. Dialysis Membrane (DM-70; MWCO 12 000) was purchased from Hi media, Mumbai, India. All other chemicals and solvents used were analytical and HPLC grade. Freshly prepared double distilled water was used in entire experiment.

\section{Preparation of ACVPL Gel}

ACVPL gels prepared by using co acervation phase separation technique with slight modification mentioned elsewhere. Transfer predetermined proportions $(1 \mathrm{mM})$ of soya phosphotidyl choline and cholesterol (1:0, 2:1, 1:1.5, 1.5:1 and 1:1) mixtures into a wide glass vial. Add 5mg of ACV followed by the addition of $400 \mathrm{mg}$ of distilled ethanol (Table 1). Close the vial appropriately to prevent the loss of alcohol. Boil the mixture on thermostat maintaining temperature between $60-65^{\circ} \mathrm{C}$ with intermittent shaking until all the contents dissolved. Add $160 \mu \mathrm{l}$ of $7.4 \mathrm{pH}$ phosphate buffer saline (PBS) maintaining same temperature in streamline manner and shake gently to get homogenous dispersion. Store the vials over night in dark place at room temperature.

\section{Formation and Morphological Evaluation}

Optical microscopy used to evaluate formation and morphology of liposomes. The morphological evaluation of ACVPL gels were carried out by hydrating with $4 \mathrm{ml}$ of $\mathrm{PBS}$ ( $\mathrm{pH} 7.4$ ), mixed gently, adjusted the volume upto $10 \mathrm{ml}$ with same buffer. The liposomes formed later hydration was evaluated by observing at magnification of 450X through optical microscope (Coslab Micro, India).

\section{Vesicle Size, Surface Charge and Entrapment Efficiency}

The prepared ACVPL gels hydrated using PBS (7.4 pH), then subjected to sonication for $5 \mathrm{~min}$ (Sonica, Milano. Italy). The obtained dispersion was used for the evaluation of vesicle size, surface charge and entrapment efficiency (EE). The mean size of formed liposomes were measured by diluting each sample and estimated photon correlation spectroscopy using Zeta sizer, nano ZS 90 (Malven instruments, Malven, UK) at $25^{\circ} \mathrm{C}$ with an angle of detection at $90^{\circ} \mathrm{C}$. Entrapment efficiency was determined by ultra filtration using filter membrane at the base of sample recovery (MW cutoff 20KDa) through centrisart (Sartorius AG, Germany) at $35000 \mathrm{rpm}$ about $15 \mathrm{~min}$. The amount of $\mathrm{ACV}$ in the aqueous system was estimated using HPLC.

\section{Determination of Spreadability}

Spreadability of gel formulations was determined as described in literature..$^{22,23}$ In brief, $0.5 \mathrm{~g}$ of different formulations was placed within a circle of $1 \mathrm{~cm}$ diameter pre-marked on a glass plate over which a second glass plate was placed. A weight of $500 \mathrm{~g}$ was allowed to rest on the upper glass plate for $5 \mathrm{~min}$. The spreadability was noted down by measuring the increase in diameter.

\section{Stability Studies}

All the prepared gel formulations were sealed in the glass vials and stored at $4^{\circ} \mathrm{C}$ and room temperature, observed for a period of 1 month for any sign of aggregation or sedimentation or leakage of drug from the vesicles. The samples were withdrawn periodically (10, 20 and 30 days) hydrated using phosphate buffered saline ( $\mathrm{pH} 7.4$ ) analysed by optical microscope and the entrapment efficiency was estimated.

\section{Rhelogical Behaviour}

The rheological properties of ACVPL gels was measured using Brookfield programmable DVIII + Digital rheometer (Masachusetts) applying a controlled stress rheometer with the cone $(24 \mathrm{~mm})$ and plate geometry. Before the study, the sample was equilibrated for $5 \mathrm{~min}$ and the torque sweep was applied in the range of 10-110\%. All the studies were performed in triplicate at an ambient temperature and the rheological behaviour was measured using Rheolac 32 software. The rheological behaviour of thixotropic fluid system is calculated by Ostwade power equation.

$\eta=\mathrm{KS}^{-\mathrm{n}}$

Where $\eta$ is the apparent viscosity, $\mathrm{k}$ is the viscosity constant, $\mathrm{s}$ is the rate of shear and $\mathrm{n}$ is the thixotropic degree which is obtained from the $\ln \eta$ Ns ln s curve.

$\ln \eta=\ln \mathrm{K}-\mathrm{n} \ln \mathrm{S}$

\section{Number of Vesicles per Cubic mm}

The copious formation of liposomal vesicles from proliposomes is one of the significant parameter to optimize the composition. Priorly, the proliposomal gels were hydrated using phosphate buffered saline $(\mathrm{pH}$ 7.4) and mounted on haemocytometer and using optical microscope. The number of liposomes converted from proliposomes per cubic $\mathrm{mm}$ was counted and calculated by using the following formula.

Total no. of liposomes formed per cubic $\mathrm{mm}=\frac{\text { Total No. of liposomes counted X Dilution factor }}{\mathrm{X}} 400$ Total No. of squares counted. 


\section{Differential Scanning Colorimetry}

Thermal properties of optimized proniosome gel (ACVPN2), Span 40 , cholesterol and ACV was studied by using differential scanning calorimeter (Mettler DSC 821e, Mettler-Toledo, Switzerland). 5 mg of sample was heated in hermitically sealed aluminium pan over a temperature range of $20^{\circ} \mathrm{C}$ to $350^{\circ} \mathrm{C}$ under a constant nitrogen gas flow of $30 \mathrm{~mL} / \mathrm{min}$ at a heating rate of $10^{\circ} \mathrm{C} / \mathrm{min}$.

\section{Fourier Transform Infrared Spectroscopy}

The optimized proniosomal gel equivalent to $5 \mathrm{mg}$ of acyclovir treated on to the prepared rat skin for $6 \mathrm{hr}$. Later treament, the skin sample was washed with water and blotted dry where untreated skin was used as control. The FTIR-spectrum of the above treated skin sample using FTIR-multipurpose spectrophotometer (Shimadzu, Japan) against untreated normal rat skin which served as the control was recorded in the range of $4000-400 \mathrm{~cm}^{-1}$.

\section{In vitro Release Study}

In vitro release study was performed to determine the ACV release pattern across the cellophane membrane $(0.45 \mu \mathrm{m}$ pore size $)$. The cellophane membrane was soaked before the study, after it was mounted between the two halves of the Franz diffusion cell. Uniformly apply the prepared proliposomal formulation on to the membrane facing towards donor compartment. Receiver compartment filled with the 7.4 pH PBS. Cover the donor compartment and sampling port using parafilm to prevent evaporation. The buffer stirred constantly $400 \mathrm{rpm}$ maintaining at $37 \pm 2^{\circ} \mathrm{C}$. Carefully withdraw $1 \mathrm{ml}$ of sample at predetermined time intervals $(0.5,1,2,4,6,8,12,18$ and $24 \mathrm{hrs})$, replace with equal volume of fresh buffer. Estimate the quantity of ACV released from all the prepared proliposomal gel and control spectro photometrically, using UV- Visible spectrophotometer maximum absorption at $251 \mathrm{~nm}$.

\section{Ex vivo Permeation Study}

Male wistar rats (180 - 200 grams) were used in ex vivo skin permeation study with prior approval of Institutional Animal Ethical Committee, Trinity College of Pharmaceutical Sciences. The animals had free access to food and water until euthanasia. The rats were sacrificed with excess ether inhalation. Depilation can be carried out on the rat abdominal skin with hair clipper, taking extreme precautions not to damage skin. The skin was excised and obliterate from adhering matter such as fat tissue, absterge capillaries with a pair of scissors. The rat epidermis was prepared by heat separation technique, ${ }^{24}$ which involves the removal of dermal portion of the skin by soaking the excised abdominal skin in boiling water at $60^{\circ} \mathrm{C}$ for $45 \mathrm{sec}$. This transient heat does not affect the barrier properties of the skin. The epidermis was washed properly using double distilled water, wrapped in aluminium foil and taxidermy was done at $-20^{\circ} \mathrm{C}$ (Used within two weeks). Prior to the study, the rat skin was brought to room temperature and placed between two halves of locally fabricated vertical Franz diffusion cell (effective diffusional area $4.59 \mathrm{~cm}^{2}$ ) stratum corneum facing towards donor compartment. The receptor compartment was filled with $17 \mathrm{ml}$ of $7.4 \mathrm{pH}$ PBS and the skin was allowed to equilibrate for $1 \mathrm{hr}$ to drain out the interfering components present in the skin if any. Carryout the permeation study by replacing with fresh $7.4 \mathrm{pH}$ PBS containing $0.003 \% \mathrm{w} / \mathrm{v}$ of sodium azide as a microbial retardant. Apply the prepared ACVPL gel and control (5 mg ACV suspended in same solvents) on the skin. Cover the donor compartment and sampling port with glass lid and parafilm respectively to prevent from evaporation of the contents. Maintain the receptor compartment under constant stirring $(400 \mathrm{rpm})$ at $37 \pm 2^{\circ} \mathrm{C}$ for $24 \mathrm{hr} .1 \mathrm{~mL}$ of sample was withdrawn at predetermined time intervals and replenished with equal volume of fresh buffer. The obtained samples were suitably diluted and quantified by HPLC.

\section{Drug Content Remained/Retained in the Skin}

The amount of ACV deposited in the epidermal skin layers was estimated after $24 \mathrm{hr}$ permeation study. The skin was removed from the diffusion cell and the adhering matter was removed by brief washing /ablution with methanol followed by drying at room temperature for $10 \mathrm{~min}$. The skin was chopped into small pieces, homogenization carried out using phosphate buffered saline ( $\mathrm{pH}$ 7.4) and subjected to sonication for 30 min (bathsonicator, Sonica, Italy) to leach out the ACV from skin layers. The samples were filtered through membrane filter $(0.45 \mu \mathrm{m})$ and estimated by HPLC.

\section{Permeation Data Analysis}

The cumulative amount of drug permeated through unit area was plotted against time. From the linear portion of the cumulative amount permeated per unit area against time steady state flux was obtained. The permeability co efficient $(\mathrm{kp})$ was calculated by correlating steady state flux with initial drug concentration. From the transdermal flux ratio between proliposomal gel and control ER (Enhancement Ratio) is calculated.

\section{Pharmacokinetic Study and Estimation of Pharmacokinetic Parameters}

Male wistar rats weighing between $180-200 \mathrm{~g}$ were used to conduct the pharmacokinetic study with the prior approval of Institutional Animal Ethical Committee, Trinity College of Pharmaceutical Sciences, Peddapalli, India. The rats were divided in to test and control groups containing six in each. Before the study the rats were prepared by careful shaving of abdominal hair with electric shaver followed by clean with water. The optimized proliposomal gel equivalent to $25 \mathrm{mg} / \mathrm{Kg}$ applied to test group and the control group received ACV oral suspension $(5 \mathrm{mg} /$ $\mathrm{ml}$ in $0.5 \% \mathrm{w} / \mathrm{v}$ of HPMC). After uniform application of proliposomal gel on to the shaved area $\left(3.14 \mathrm{~cm}^{2}\right)$ was covered with impermeable backing membrane followed by adhesive membrane. The rats under testing maintained carefully in separate cages through out the study. Blood samples $(500 \mu \mathrm{l})$ were collected at predetermined time intervals from the retro orbital plexus in to the heparinised micro centrifuge. Blood plasma separated through centrifugation at $10000 \mathrm{rpm}$ for $10 \mathrm{~min}$ and stored in freeze at $-20^{\circ} \mathrm{C}$ for further study. The proportion of ACV in blood plasma can be estimated by the method mentioned by Sanjay et al. ${ }^{18}$ The blood plasma samples were freeze thawed to room temperature. Then the plasma proteins precipitated by treating $0.1 \mathrm{ml}$ of blood plasma and with equal volume of HPLC grade $10 \%(\mathrm{v} / \mathrm{v})$ trichloro acetic acid and $50 \mu \mathrm{L}$ of acetonitrile acid. The treated mixture vortexed for 30 seconds, followed by centrifugation (10000 rpm for $10 \mathrm{~min}$ ) at room temperature. Filter the supernatant using $0.4 \mu \mathrm{m}$ Syringe filter, quantify the ACV content by injecting into HPLC.

The pharmacokinetic parameters like Maximum Concentration $\left(\mathrm{C}_{\max }\right)$ and Maximum Time $\left(\mathrm{T}_{\max }\right)$ estimated directly from the blood plasma concentration Vs time profile. Trapezoidal rule used for calculation of AUC $\left(\mathrm{AUC}_{0-\mathrm{t}}\right)$. $\mathrm{AUC}_{\mathrm{t}-\infty}$ was calculated by using the following formula.

AUC $\mathrm{t}-\infty=\frac{\text { Plasma concentration at last time point }}{\text { Elimination rate constant }(\mathrm{K})}$

and

Relative bioavailability $(\mathrm{F})=\frac{\mathrm{AUC} 0-\infty \text { of ACV containing proliposomal gel }}{\mathrm{AUC} 0-\infty \text { of } \operatorname{control}(\text { Oral suspension })}$ 


\section{HPLC Assay of ACV}

HPLC system (Shimadzu Corporation, Kyoto, Japan) equipped with LC-10 AT VP Liquid Chromatograph pump, SPD-10A AVP UV-Spectrophotometric detector, Spinchrom software and injector (Rheodyne) fitted with a $20 \mu \mathrm{L}$ capacity was used for the analysis. An octadecylsilane (C-18) reverse phase stainless steel analytical column $(250 \times 4.6 \mathrm{~mm}$ ) with $5 \mu \mathrm{m}$ particle size (Lichrospher 100) was employed for chromatographic separation. Mobile phase: 0.02M Potassium dihydrogen phosphate, $\mathrm{pH} 3.5$ and Acetonitrile (95:5). Flow rate: one $\mathrm{mL}$ per minute, $\mathrm{UV}$ detection at $254 \mathrm{~nm}$ and separation was at ambient temperature and the sensitivity was set at 0.005 AUFS.

\section{Skin Irritation Test}

The skin irritation test was conducted on the male wistar rats. The proniosomal gel formulations were applied on to the dorsal side of the cleanly shaved rats and observed for any sign of irritation or reddening for a period of one week.

\section{RESULTS}

\section{Formulation and Characterization of Acyclovir Proliposome gels}

In Acyclovir proliposomes, the lipid mixture comprising Soya phosphotidyl choline and cholesterol were used in varying molar ratios and in all formulations ethanol $(400 \mathrm{mg})$ and water $(160 \mathrm{mg})$ were used in constant amounts. The provesicular gels appeared to be yellow liquid, yellowish translucent gel and creamy white gel. Figure 1 envisages the spontaneous formation of liposmes from Provesicular gels upon contact with water.

The size of the proliposome formulations was within the range of 385 to $616 \mathrm{~nm}$ (Table 2). The zeta potential of the proliposome formulation without cholesterol (ACVPL1) was $-4.3 \pm 2.1 \mathrm{mV}$ and the incorporation of cholesterol (ACVPL2) led to a significant increase in ZP to $-13.12 \pm 3.4$ $\mathrm{mV}$ (Table 2). However, significant change could not noticed in ZP with further increase in cholesterol concentration. The entrapment efficiency was found to be between 78 to $94 \%$. Small value of polydispersity index $(\mathrm{PI})(<0.1)$ indicates a homogenous population, while a PI $(>0.3)$ indicates a higher heterogeneity. The polydispersibility index of all the formulations was within the acceptable limits.

The entrapment efficiency of the proliposome formulation without cholesterol (ACVPL1) was found to be $78.4 \pm 2.3 \%$. The presence of cholesterol has increased the entrapment efficiency significantly of proliposome formulations (Table 2). The present research results also support the hypothesis explained in the literature reports. ${ }^{25}$ The number of vesicles formed from the hydration of provesicular formulation is an important parameter to be considered for the optimization of the variables and an abundant formation of vesicles observed in case of all formulations (Table 2). More number of vesicles per cubic mm 4.0 $\times 10^{4}$ with ACVPL2 formulation compared to other formulations was observed.

Spreadability is an important parameter for acceptance of topical formulation. The observed spreadability values were higher for gel formulations which suggest the ease of application onto the skin. The formulated gels were translucent, pseudo plastic in nature and spreadable with good skin feel (Figure 1).

The rheological characteristics plays pivotal role for the formulations meant for transdermal route. PC imparts gel like consistency and cholesterol increases micro viscosity by generating a thin film surrounding the vesicle. Viscosity of the formulations decreases with increased shear rate which reveals the shear thinning property of prepared Proliposomal gels shown in Figure 2 suitable for topical application.

Table 1: Composition and Appearance of ACV loaded Proliposomal Gels.

\begin{tabular}{ccccccc}
\hline $\begin{array}{c}\text { Formulation } \\
\text { Code }\end{array}$ & $\begin{array}{c}\text { Molar Ratio } \\
\text { (PC:Chol) }\end{array}$ & PC (mg) & $\begin{array}{c}\text { Chol } \\
(\mathrm{mg})\end{array}$ & Ethanol (mg) & $\begin{array}{c}\text { Water } \\
(\mathrm{mg})\end{array}$ & Appearance \\
\hline ACV PL-1 & $1: 0$ & 750 & - & 400 & 160 & Yellow liquid \\
ACV PL-2 & $2: 1$ & 495 & 127 & 400 & 160 & Translucent Yellowish gel \\
ACV PL-3 & $1.5: 1$ & 450 & 154 & 400 & 160 & White creamy gel \\
ACV PL-4 & $1: 1$ & 375 & 193 & 400 & 160 & White creamy gel \\
ACV PL-5 & $1: 1.5$ & 300 & 231 & 400 & 160 & White creamy gel \\
\hline
\end{tabular}

PC and Chol- indicates Phosphotidyl choline and cholesterol respectively.

Total $1 \mathrm{mM}$ lipid mixture was used in all the preparations

Table 2: Size, Zeta Potential, Entrapment Efficiency and Thixotropic Degree of ACV proliposomal formulations.

\begin{tabular}{cccccccc}
\hline $\begin{array}{c}\text { Formulation } \\
\text { code }\end{array}$ & $\begin{array}{c}\text { Size } \\
(\mathrm{nm})\end{array}$ & $\begin{array}{c}\text { Zeta Potential } \\
(\mathrm{mV})\end{array}$ & PDI & $\begin{array}{c}\text { Entrapment } \\
\text { Efficiency }(\%)\end{array}$ & $\mathrm{n}$ & $\begin{array}{c}\text { Spreadability } \\
(\mathrm{cm})\end{array}$ & $\begin{array}{c}\text { Number of vesicles } \\
\text { per cubic mm. X10 }\end{array}$ \\
\hline ACVPL-1 & $385 \pm 20$ & $-4.31 \pm 2.1$ & 0.224 & $78.4 \pm 2.3$ & 0.957 & $5.97 \pm 0.20$ & 2.3 \\
ACVPL-2 & $422 \pm 15$ & $-13.12 \pm 3.4$ & 0.289 & $94.6 \pm 3.5$ & 0.952 & $6.15 \pm 0.14$ & 4.0 \\
ACVPL-3 & $436 \pm 18$ & $-11.06 \pm 1.1$ & 0.212 & $93.4 \pm 2.1$ & 0.982 & $5.96 \pm 0.19$ & 3.5 \\
ACVPL-4 & $512 \pm 23$ & $-9.25 \pm 3.0$ & 0.206 & $89.1 \pm 1.2$ & 0.967 & $5.78 \pm 0.16$ & 2.6 \\
ACVPL-5 & $616 \pm 16$ & $-10.22 \pm 2.2$ & 0.232 & $88.7 \pm 1.7$ & 0.982 & $5.70 \pm 0.15$ & 2.9 \\
\hline
\end{tabular}

n, PDI indicates thixotropic degree, Poly Dispersity Index respectively. 
Thixotropic degree (n) is an important rheological property of gels which deals with the thinning of gel when constant force is applied. It is clearly evident from Table 2, that the thixotropic degree mainly depends on the cholesterol concentration that higher the cholesterol concentration lowers the Thixotropic degree.

\section{In vitro drug release study}

To understand the in vitro release behaviour of ACV from proliposomes was studied. Figure 3 illustrates the percentage drug release from different formulations. The release of ACV from control was nearly $75 \%$ within $12 \mathrm{~h}$ which clearly suggest the permeability of the membrane and prevalence of the sink condition for the drug. A typical biphasic release pattern was observed with proliposome formulations. Initially a rapid burst release followed by sustained release for a period of $24 \mathrm{~h}$ was observed (Figure 3). The high concentration gradient prevailing at the initial time points might have contributed for the rapid drug release and also may be due to the faster release of unentrapped drug from the proliposome formulations. However further increase in cholesterol concentration led to an increase in drug release which could be due to the disordered bilayer or more rigidity of the membrane. The in vitro release data is in correlation with the entrapment efficiency results.

\section{Ex vivo permeation studies}

The steady state flux and permeability coefficient were very much higher for the proliposome gel formulation (ACVPL2) containing 2:1 ratio of phospholipid:choleterol. The enhancement ratio well above 1 indicates improved permeation and it was observed ER greater than 1 for all proliposome gel formulations compared to control. Such an improvement

Table 3: In vitro release kinetics of ACV from proliposomal gels across cellophane membrane ( $n=3)$.

\begin{tabular}{|c|c|c|c|c|c|}
\hline \multirow{2}{*}{$\begin{array}{l}\text { Formulation } \\
\text { code }\end{array}$} & \multicolumn{2}{|c|}{ Zero order } & \multicolumn{2}{|c|}{ First order } & \multirow{2}{*}{$\begin{array}{c}\text { Higuchi } \\
R^{2} \\
\end{array}$} \\
\hline & $\mathrm{K}_{0}\left(\mathrm{~h}^{-1}\right)$ & $R^{2}$ & $\mathrm{~K}_{0}\left(\mathrm{~h}^{-1}\right)$ & $R^{2}$ & \\
\hline Control & 0.440 & 0.797 & 0.486 & 0.549 & 0.901 \\
\hline ACVPL-1 & 0.213 & 0.877 & 0.581 & 0.601 & 0.946 \\
\hline ACVPL-2 & 0.173 & 0.962 & 0.503 & 0.653 & 0.949 \\
\hline ACVPL-3 & 0.196 & 0.861 & 0.553 & 0.605 & 0.946 \\
\hline ACVPL-4 & 0.219 & 0.857 & 0.562 & 0.624 & 0.845 \\
\hline ACVPL-5 & 0.248 & 0.872 & 0.767 & 0.624 & 0.935 \\
\hline
\end{tabular}
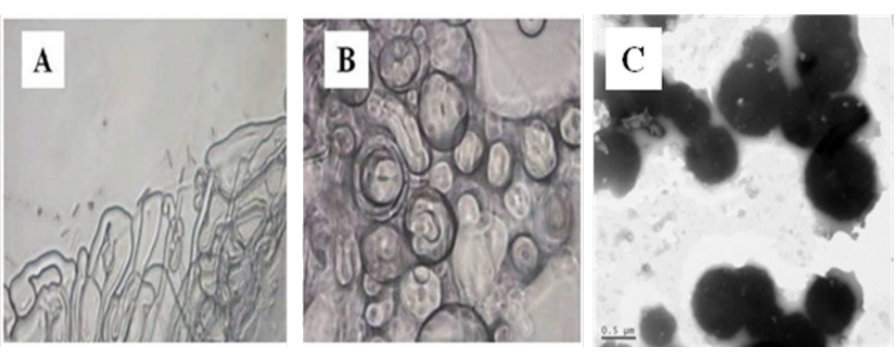

Figure 1: Microscopic photo graphs (at magnification of 450X) showing the formation of liposomes from proliposome formulation upon hydration with $7.4 \mathrm{pH}$ PBS. A) Up on contact with water tubular structures are forming B) Conversion in to small size spherical shaped acyclovir liposome vesicles after ruptured by complete hydration. C) TEM image of spherical vesicles of acyclovir liposomes from proliposomes.

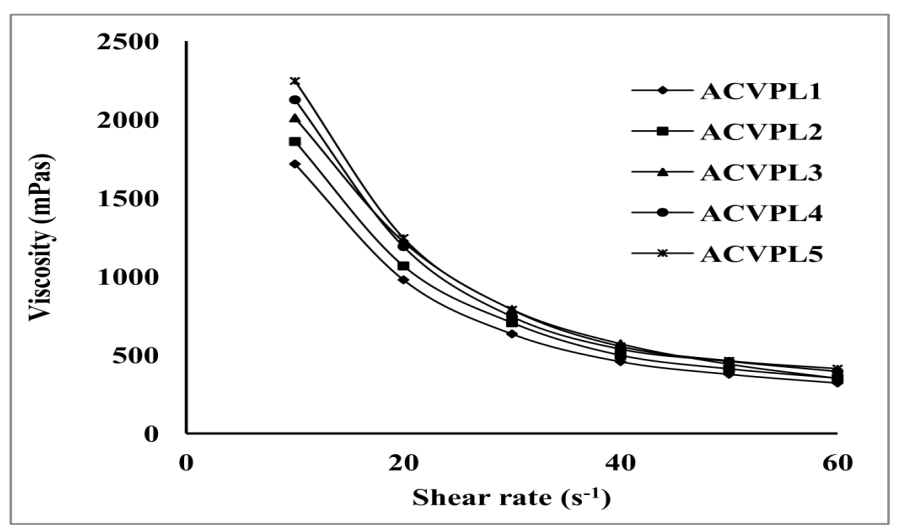

Figure 2: Rheograms of various ACV proliposomal gel formulations.

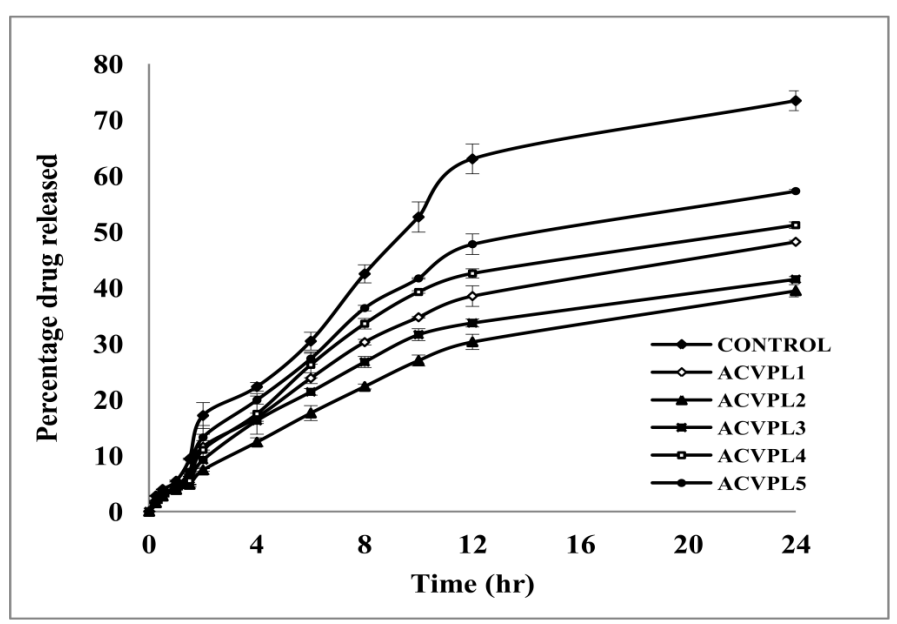

Figure 3: In vitro release profile of ACV from various proliposomal formulations across the cellophane membrane (mean $\pm S D ; n=3$ ).

is statistically significant (Table 4). Based on the permeation parameters the formulations can be ranked in the following decreasing order.

ACVPL2 > ACVPL1 >ACVPL3 > ACVPL4 >ACVPL5 > Control

\section{Drug content retained in the skin}

The extent of drug content in the skin layers upon treatment of rat skin with all the proliposome formulations and drug solution was shown in Figure 6. Since the permeation was increased with all the proliposome formulations, obviously the drug in the skin layers was also increased. This can be well explained based on the fact that the saturation of skin layers at the termination point of the experiment i.e. $24 \mathrm{~h}$ could have led to the higher drug deposited in the skin values. 


\section{Pharmacokinetic studies}

The plasma concentration Vs time profile following oral administration and transdermal application of proliposome formulation is shown in Figure 9. The ex vivo and in vivo correlation was done between the cumulative amount permeated $(\mu \mathrm{g})$ and AUC $\left(\mu \mathrm{g} \mathrm{h} \mathrm{mL} \mathrm{mL}^{-1}\right)$. The higher regression coefficient with an $R^{2}$ value of 0.9903 indicates point to point correlation following level A correlation.

\section{Stability studies}

The change in morphological behaviour was monitored periodically. The change in physical appearance, vesicle size and entrapment efficiency were evaluated every 10 days up to 30 days (Figures 10a, 10b, 11a and

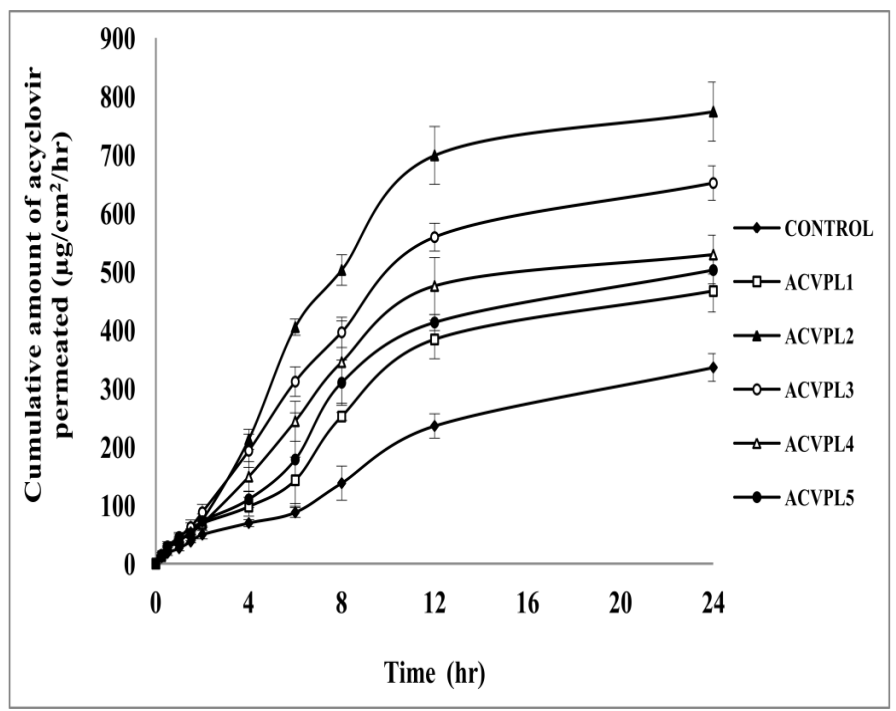

Figure 4: Cumulative Amount of ACV permeated from various proliposomal gel formulations through the rat skin ( $m e a n \pm S D ; n=3$ ). 11b). Significant $(p<0.05)$ morphological changes could not found from the microscopical examinations.

\section{DISCUSSION}

The method of preparation of provesicular gel was based on the principle of coacervation phase separation technique. The concentrated mixture of phospholipid with alcohol and aqueous phase can spontaneously convert into stable liposome dispersion upon contact with water. Soy Phosphotidyl choline is a natural permeation enhancer and acts as surfactant. It fluidizes the stratum corneum and alters its barrier function by Induced structural rearrangement, intercalates with stratum corneum lipids. At the kraft point temperature $\left(\mathrm{T}_{c}\right)$, soy phosphatidyl choline forms lamellar bilayer sheets intervening with the aqueous layer

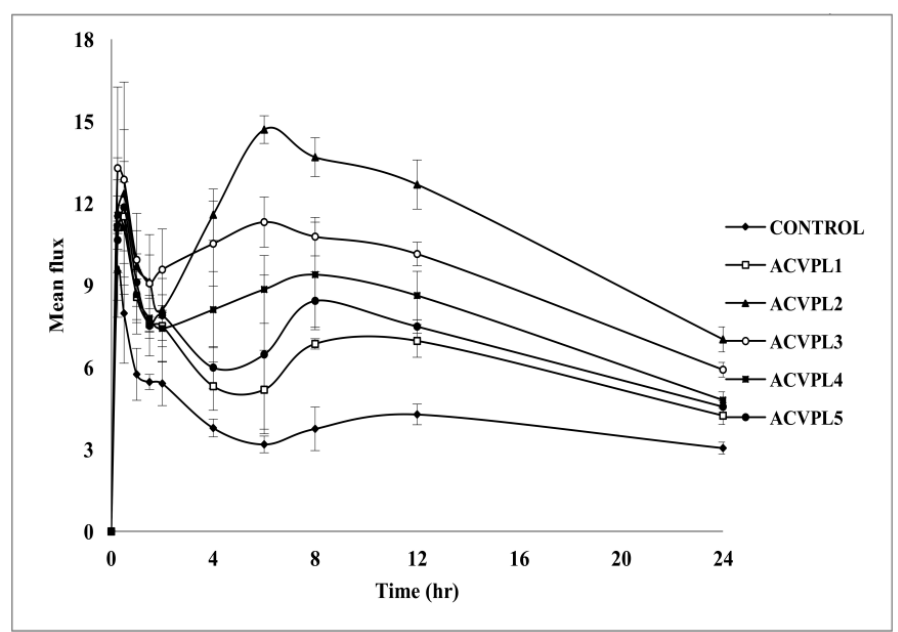

Figure 5: Mean flux ACV from different proliposomal gel formulations across rat skin (mean $\pm S D ; n=3$ ).

Table 4: Permeation parameters of ACV from different proliposomal formulations across rat skin (mean \pm SD; $n=6$ ).

\begin{tabular}{cccccc}
\hline $\begin{array}{c}\text { Formulation } \\
\text { code }\end{array}$ & $\mathrm{Q}_{24}(\mu \mathrm{g})$ & Jss $\left(\mu \mathrm{g} / \mathrm{cm}^{2} / \mathrm{h}\right)$ & $\mathrm{Kp}(\mathrm{cm} / \mathrm{h}) \times 10^{-3}$ & ER & DCS \\
\hline Control & $1489.24 \pm 21.92$ & $13.69 \pm 0.87$ & $2.74 \pm 0.17$ & - & $481.54 \pm 28.73$ \\
ACVPL-1 & $2068.16 \pm 38.27$ & $19.00 \pm 2.221$ & $3.80 \pm 0.44$ & 1.39 & $1145.83 \pm 28.29$ \\
ACVPL-2 & $3431.98 \pm 32.23$ & $29.98 \pm 1.971,2,4,5,6$ & $5.97 \pm 0.43$ & 2.18 & $892.44 \pm 34.43$ \\
ACVPL-3 & $2891.91 \pm 42.83$ & $24.60 \pm 1.811,2,6$ & $4.92 \pm 0.36$ & 1.80 & $856.73 \pm 37.01$ \\
ACVPL-4 & $2346.62 \pm 35.28$ & $20.36 \pm 0.621$ & $4.08 \pm 0.12$ & 1.49 & $753.40 \pm 21.92$ \\
ACVPL-5 & $2230.06 \pm 28.75$ & $20.44 \pm 1.541$ & $4.03 \pm 0.34$ & 1.47 & $628.94 \pm 53.01$ \\
\hline
\end{tabular}

$p<0.05 ; \mathrm{Q}_{24}$, Jss, Kp, ER, DCS represents amount permeated in 24h, steady state Flux,

Permeability coefficient, Enhancement Ratio, Drug Content retained in the Skin layers respectively.

1,2,3,4,5 represents control, ACVPL1, ACVPL2, ACVPL3, ACVPL4 and ACVPL5 respectively.

Table 5: Pharmacokinetic parameters of ACV in Rats Following Administration of Proliposome Gel (PL gel) and Control (Oral Suspension) $(n=6)$.

\begin{tabular}{cccccccc}
$\begin{array}{c}\text { FORMULATION } \\
\text { CODE }\end{array}$ & $\mathrm{C}_{\max }(\mu \mathrm{g} / \mathrm{mL})$ & $\begin{array}{c}\mathrm{T}_{\max } \\
(\mathrm{hr})\end{array}$ & $\begin{array}{c}\mathrm{AUC}_{0-\mathrm{t}} \\
\mu \mathrm{ghrmL}\end{array}$ & $\begin{array}{c}\mathrm{AUC}_{\mathrm{t}-\infty} \\
\mu \mathrm{ghrmL}\end{array}$ & $\begin{array}{c}\mathrm{AUC}_{0-\infty} \\
\mu \mathrm{ghrmL}\end{array}$ & $\begin{array}{c}\mathrm{K} \\
(\mathrm{hr})\end{array}$ & $\mathrm{F}$ \\
\hline CONTROL & $0.598 \pm 0.010$ & $2.00 \pm 0.00$ & $4.75 \pm 0.09$ & $1.06 \pm 0.132$ & $5.81 \pm 0.21$ & 0.048 & - \\
& $0.32 \pm 0.021$ & $6.00 \pm 0.00$ & $6.27 \pm 0.11$ & $12.52 \pm 1.13$ & $18.78 \pm 1.18$ & 0.015 & 3.24 \\
\hline
\end{tabular}




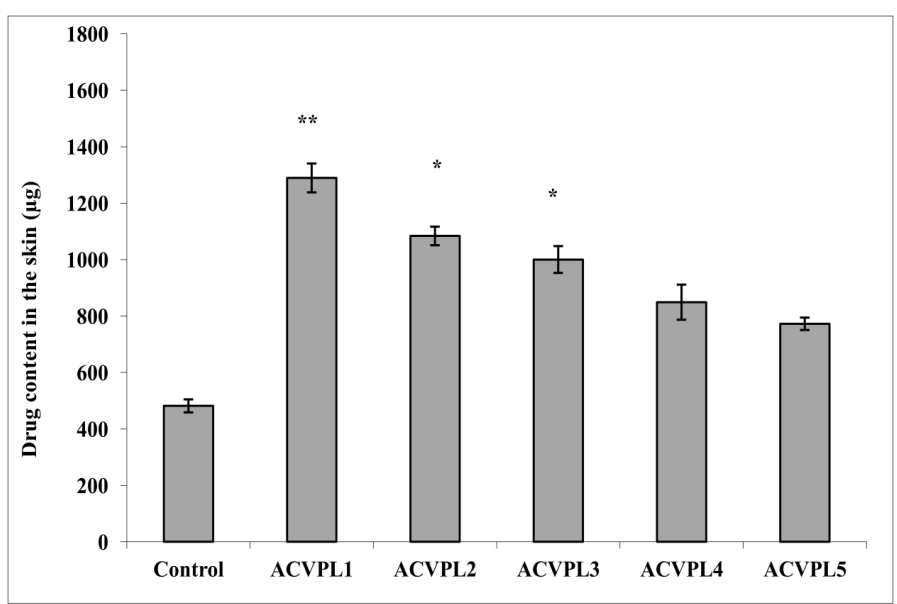

Figure 6: Drug deposited in the skin layers after $24 \mathrm{~h}$ following treatment with different proliposomal gel formulations (mean $\pm \mathrm{SD} ; n=3$ ).

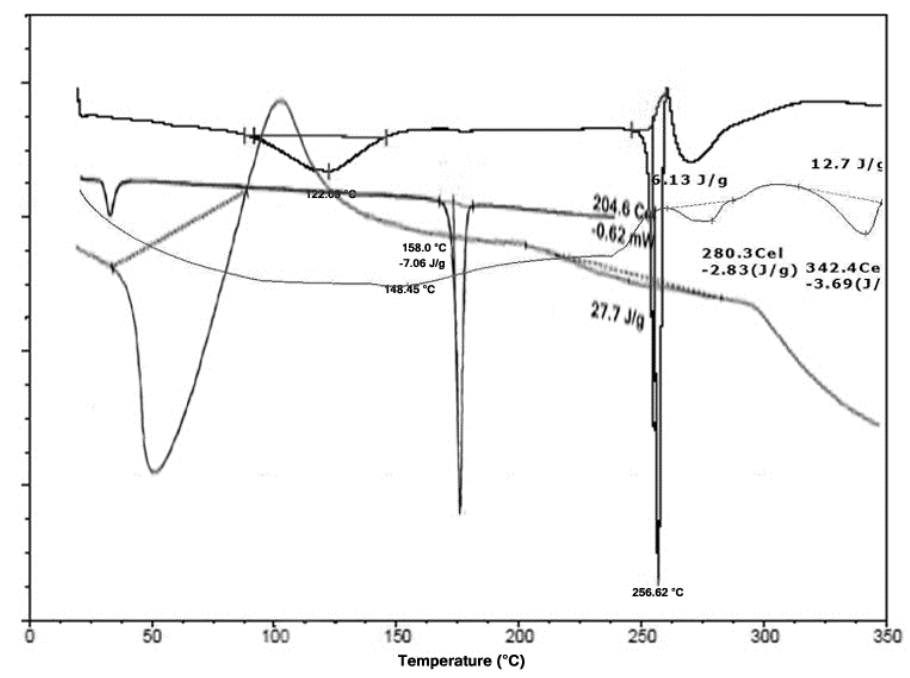

Figure 7: DSC thermograms of A) Acyclovir B) cholesterol C) PC D) optimized proliposome gel formulation (ACVPL2).

to form transdermally suitable lamellar liquid crystalline gel organized by soy phosphatidyl choline and cholesterol. When the gel is applied topically under in situ occlusive conditions, the water absorbed from the skin beneath layers and the proliposomes convert into liposomes. The fatty acid hydrophobic tail of soy phosphotidyl choline ionizes to give negative zeta potential and an increase in the concentration increases the hydrophobic concentration thereby helps in increasing vesicle stability by generation of repulsion among the hydrophobic tail.

The primary concern in the scale up of vesicular formulations is to impart stability. Cholesterol is added along with phospholipid as it is known as structural lipid which improves the stability and in turn augmenting the entrapment efficiency. The morphology of the vesicles is dependent on the concentration of cholesterol and phospholipid. The effect of cholesterol was studied by varying the composition of phospholipid to cholesterol ratio keeping the total lipid constant.

Initially tubular structures were formed upon swelling of the phospholipid and subsequent conversion into multilamellar vesicles spherical in shape. Further the TEM image confirms the shape and the type of the liposomes formed from proliposomes (Figure 1). Addition of cholesterol brought a significant change in the appearance of the formulation which led to yellowish translucent gel from liquid state. However, further increase in

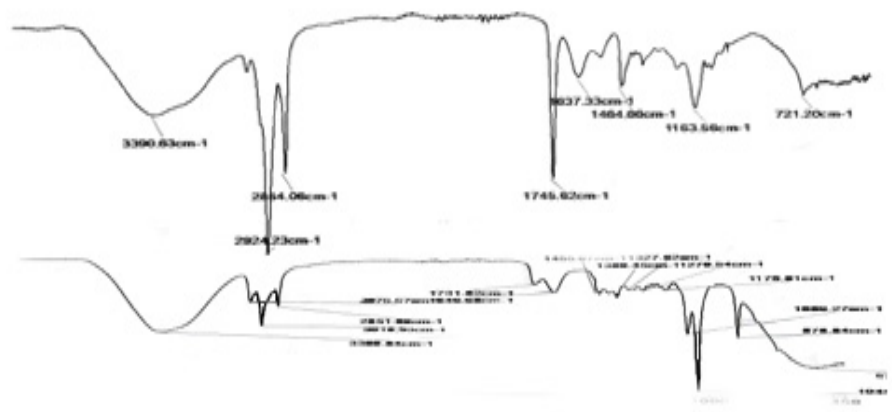

Figure 8: FTIR spectra of A) untreated rat skin (Control) B) rat skin treated with optimized ACV containing proliposome gel formulation (ACVPL2).

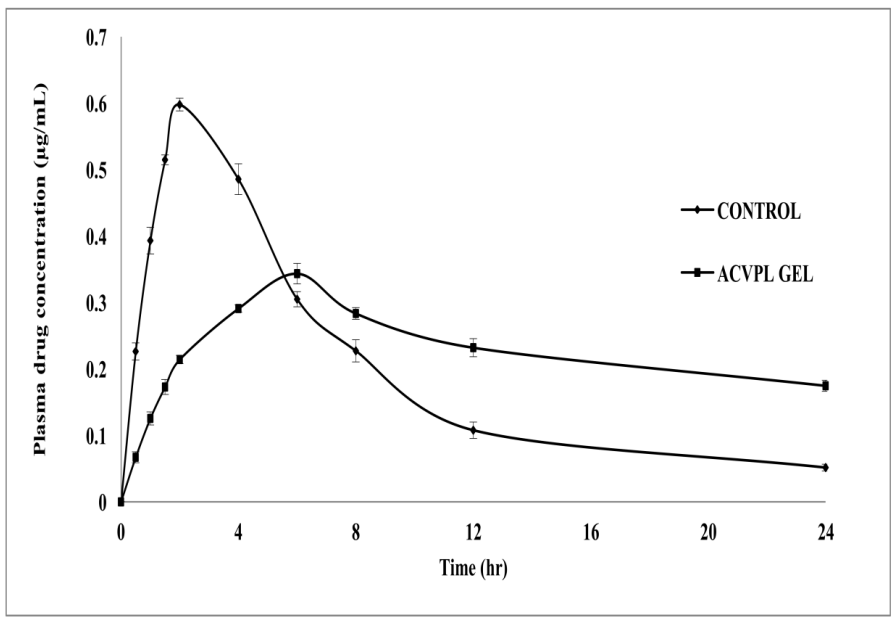

Figure 9: Mean plasma concentration Vs Time profile of ACV followed by the treatment with optimized ACVPL gel (ACVPL2) and Control (mean \pm SD; $n=6$ ).

the cholesterol concentration creamy white gel was obtained. The size of the vesicles was linearly increased with increase in the concentration of cholesterol in the formulations.

The reason for an increase in entrapment efficiency with the presence of cholesterol can be attributed to the increased hydrophobicity and stability of the bilayer formed and thereby reducing the drug leakage. In contrary, the entrapment efficiency was reduced with an increase in the concentration of cholesterol in proliposome formulations which could be due to the competition of high amount of cholesterol with the drug for the embedment in the bilayer and also may lead to perturbation of the regular linear structure of bilayer impeding the accommodation of the drug. ${ }^{26}$

The DSC thermogram clearly shows the disappearance of the transition peak of ACV in proliposome formulation which is obviously due to the molecular state of the drug in phospholipid and cholesterol mixture (Figure 7). The bands at 2922 and $2852 \mathrm{~cm}^{-1}$ present in the functional group region of FTIR spectra can be attributed to the asymmetric $\mathrm{CH} 2$ and symmetric $\mathrm{CH} 2$ vibrations of long chain hydrocarbons of lipids (Figure 8). The peak height and area is proportional to amount of lipids present gets reduced if any extraction of lipids from stratum corneum results. The reduction in peak area suggests that the fluidization of 

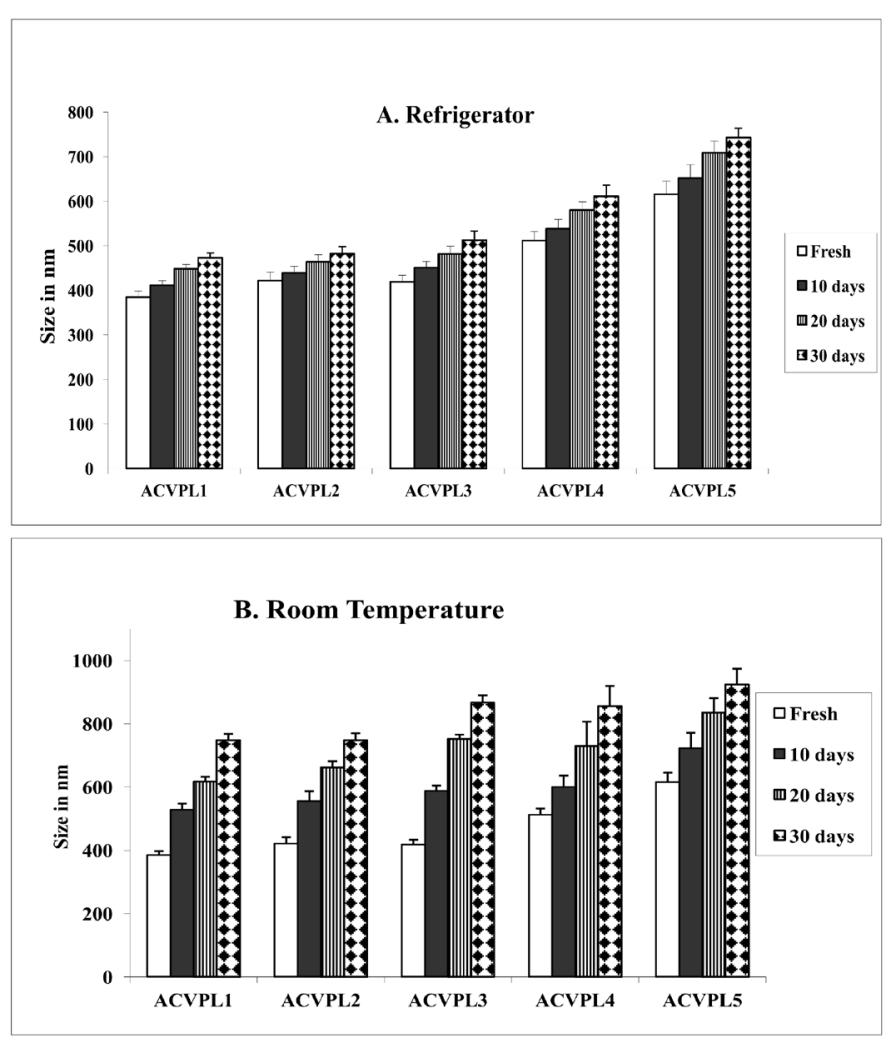

Figure 10: Change in Particle size ACV containing proliposomal gel formulations during storage A) Refrigerator B) Room Temperature.

the stratum corneum due to the fusion of the vesicle bilayer with skin membrane.

The in vitro drug permeation data was subjected to mathematical treatment to know the kinetics and mechanism of drug release from the proliposome formulations. The data suggest that the drug release from proliposome formulations is diffusion controlled following zero order kinetics (Table 3).

The ex vivo permeation study was conducted across the rat abdominal skin and the cumulative amount of drug permeated is depicted in Figure 4. The significant permeation of ACV results only when the drug is released from the liposomes formed after the hydration of proliposome gel with the skin fluids. ${ }^{27}$ No lag time was observed in all the formulations which clearly indicate the formation of liposomes. Moreover, the drug was detected within $0.25 \mathrm{~h}$ which explains the procedures of diffusion of water from the receptor fluid to the skin membrane, release of drug and permeation across the skin occurred rapidly. ${ }^{28}$ The permeation enhancement assessed in terms of permeation parameters (flux, permeability coefficient and enhancement ratio) were calculated and shown in Table 4 . The permeation was very much less for the formulation without cholesterol which might be due to the improper formation of vesicles, less stability and poor entrapment of the drug. A significant improvement in permeation was observed with inclusion of cholesterol into the formulation. However further increase in cholesterol concentration led to decrease in permeation which could be due to the high hydrophobicity of vesicle which might have reduced the partitioning promotion of ACV into the skin bilayers. The maximum flux obtained was $13.69 \pm 0.87$ and $19.00 \pm 2.22 \mu$ g.h.cm ${ }^{2}$ from control and proliposome formulation without cholesterol respectively. However the flux was higher at all time points for the proliposome gel formulations compared to control and no cholesterol which indicates the controlled delivery of ACV from proliposome gel formulations (Figure 5). Interestingly, the amount of drug released across the cellophane membrane was significantly lower than the permeation across skin, indicates the barrier properties of the skin. This also suggests that the vesicle skin interaction and direct contact of vesicle with skin are important attributable factors for improved transdermal delivery of ACV. ${ }^{29}$ The present research results are also well correlated with the reports. ${ }^{30}$ Overall it is evident from the results that the permeation of $\mathrm{ACV}$ has been greatly improved from proliposome gel formulations. In the literature, several mechanisms have been put forward to explain the factors contributing for the improved permeation of drugs from proliposomes. Cholesterol and phospholipids are known to interact with intercellular lipids present in the stratum corneum and there upon modify the structural and permeability characteristics making it more permeable to the drugs. ${ }^{31}$ To summarize, several mechanisms in combination might have played a significant role in enhancing the permeation of ACV through proliposome gel formulations.

The higher deposition of ACV in skin layers with proliposome gels compared to control reveals the potential of these formulations in avoiding the barrier function of the stratum corneum and delivering the drug efficiently into the viable regions of the skin for improved bioavailability. After application of optimized proliposome gel formulations (ACVPL2), any marked erythema was not observed during seven days.

The objective of the present study was to evaluate the feasibility of transdermal delivery of ACV loaded proliposome gels for improved bioavailability. Since the oral absorption of ACV is highly variable with a low bioavailability ranging from 10 to $30 \%,{ }^{32}$ a transdermal delivery may provide a means for the sustained delivery of ACV with minimal fluctuations in the systemic circulation. It is evident from the Figure that the time to reach maximum concentration $\left(\mathrm{T}_{\max }\right)$ was higher for the control compared to proliposomes. This is obviously due to the ready availability of the drug from suspension with an enhanced effective surface area and good membrane contact for absorption across GI membrane. The slow elimination of ACV from systemic circulation indicates the sustained delivery of ACV from proliposomes. The extent of absorption described by AUC was significantly higher for ACVPL gel compared to control $(p<0.05)$ (Table 5). The enhancement in the bioavailability assessed in terms of AUC and F was increased by 3.24 fold with proliposome formulation $(p<0.001)$ (Table 5). The significant enhancement in bioavailability with proliposome compared to control could be due to the avoidance of pre-systemic metabolism which is responsible for poor bioavailability of the $\mathrm{ACV}$.

However, slight increase in micro viscosity and integrity of proliposomal gels was observed in stability studies. This may be due to during storage water molecules intercalate with polar head groups of lecithin results in slight increase in gel consistency. Concomitant evaporation of little portion of ethanol also improves in micro viscosity. A significant increase of particle size observed up on storing at room temperature indicates the effect of temperature. Competence of cholesterol with ACV in hydrophobic bilayer resulted in slight reduction of entrapment efficiency of all the formulations except ACVPL1 (without cholesterol) $(p<0.05)$ during storage at room temperature. No congealing observed on storage at $4^{\circ} \mathrm{C}$. The formulations were more stable at $4^{\circ} \mathrm{C}$ compare to room temperature.

\section{CONCLUSION}

Acyclovir containing proliposomal gels formulated by co acervation phase separation method and successfully developed. All the prepared ACVPL gels evaluated for its morphological characters. The optimized formulation (ACVPL2) showed highest entrapment efficiency (94 \pm 3.5 ). Effect of cholesterol was also evaluated. Significant higher increment 
in enhancement ratio assessed from all the ACVPL gels compared to control. 3.24 fold increment in bioavailability of ACVPL2 than control reveals the potential of proliposomes in releasing of drug applied through transdermal route. Stability studies were performed to evaluate the stability of proliposomes. All the proliposomal formulations were more stable at refrigerator temperature.

\section{ACKNOWLEDGEMENT}

The authors are very much thankful to Lipoid, Germany for providing the gift sample of Phospholipon 90G. The authors also thank Mr. Dasari Prashanth Reddy, Chairman, Trinity College of Pharmaceutical Sciences for providing the necessary facilities.

\section{CONFLICT OF INTE REST}

The authors confirm that this research article has no conflict of interest.

\section{ABBREVIATIONS}

ACV: Acyclovir; PC: Phosphotidyl choline; SC: Stratum corneum; DSC: Differential scanning colorimetry; FTIR: Fourier Transform Infrared Spectroscopy.

\section{REFERENCES}

1. Wu PC, Huang YB, Chang JJF, Chang JS, TsaiYH. Evaluation of pharmacokinetics and pharmacodynamics of captopril from transdermal hydrophilic gel in normotensive rabbit and spontaneously hypertensive rats. Int $\mathrm{J}$ Pharm. 2000;209(1-2):87- 94.

2. Manuel S, Laetiti F, Emmanuelle $H$, Isabelle $L$, Eleonore HU. Ex vivo transdermal absorption of a liposome formulation of diclofenac. Biomedicine and Pharmacotherapy. 2019;111:785-90.

3. Manosroi A, Khanrin P, Lohcharoenkal W, Werner RG, Gotz F, Manosroi W, et al. Transdermal absorption enhancement through rat skin of gallidermin loaded in niosomes. Int J Pharm. 2010;392(1-2):304-10.

4. Sakdiset P, Amnuaikit T, Pichayakorn W, Pinsuwan S. Formulation development of ethosomes containing indomethacin for transdermal delivery. J Drug Del Sci Tech. 2019:52:760-8

5. Das B, Sen SO, Maji R, Nayak AK, Sen KK. Transferosomal gel for transdermal delivery of risperidone: Formulation optimization and ex vivo permeation. I Drug Del Sci Tech. 2017;38:59-71.

6. Afzal H Mohammad AA, Sultan A, Syed S, Sandeep KS. Vesicular elastic liposomes for transdermal delivery of rifampicin: In-vitro, in-vivo and in silico GastroPlus ${ }^{\text {TM }}$ prediction studies. Eur J Pharm Sci. 2020;151:105411.

7. Suresh B, Swetha G, Basanth BE, Raju J, Prabhakar RV. Proliposomes of lisinopril dihydrate for transdermal delivery: Formulation aspects and evaluation. Korean J Chem Eng. 2013;30(8):1659-66.

8. Raju J, Sruthi S, Suresh B, Prabhakar RV. Enhanced Bioavailability of Exemestane Via Proliposomes based Transdermal Delivery. J Pharm Sci. 2011;100(8):320822.

9. Varshosaz J, Pardakhty A, Seied MHB. Sorbitan monopalmitate-based proniosomes for transdermal delivery of chlorpheniramine maleate. Drug Deliv. 2005;12(2):75-82.

10. Gupta A, Prajapati SK, Balamurugan M, Singh M, Bhatia D. Design and development of a proniosomal transdermal drug delivery system for captopril.
Trop J Pharm Res. 2007;6(2):687-93

11. Diez-Sales O, Garrigues TM, Herraez JV, Belda R, Martin-Villodre A, Herraez M. In vitro percutaneous penetration of acyclovir from solvent systems and Carbopol 971-P hydrogels: Influence of propylene glycol. J Pharm Sci. 2005:94(5):1039-47.

12. Parry GE, Dunn P, Shah VP, Pershing LK. Acyclovir Bioavailability in Human Skin. J Invest Dermatol. 1992:98(6):856-63.

13. Afouna MI, Mehta SC, Ghanem AH, Higuchi WI, Kern ER, De CE, et al. Assessment of correlation between skin target side free drug concentration and the in vivo topical antiviral efficacy in hairless mice for (E)-5-(2- bromovinyl)20-deoxyuridine and acyclovir formulations. J Pharm Sci. 1998;87(8):917-21.

14. Parry GE, Dunn P, Shah VP, Pershing LK. Acyclovir bioavailability in human skin. J Invest Dermatol. 1992;98(6):856-63.

15. Chinmay S, Friden P, Ravi J, Grazia S. In vivo quantification of acyclovir exposure in the dermis following iontophoresis of semisolid formulations. J Pharm Sci. 2009;98(3):917-25.

16. Nadia MV, Sara N, Carlo L, Paolo C, Patrizia S. In vitro acyclovir distribution in human skin layers after transdermal iontophoresis. J Control Rel. 1998;50(13):291-6.

17. $\mathrm{Xu} \mathrm{Q}$, Ibrahim SA, Higuchi WI, Li SK. Ion-exchange membrane assisted transdermal iontophoretic delivery of salicylate and acyclovir. Int J Pharm. 2009;369(1-2):105-13.

18. Sanjay KJ, Gupta Y, Jain A, Rai K. Enhanced Transdermal Delivery of Acyclovir Sodium via Elastic Liposomes. Drug Deliv. 2008;15(3):141-7.

19. Bhavana V, Ajay JK, Jain NK. Proniosome based transdermal delivery of levonorgestrel for effective contraception. J Control Rel. 1998;54(2):149-65.

20. Jia-You F, Tsong-Long $H$, Yen-Ling $H$, Chia-Lang $F$. Enhancement of the transdermal delivery of catechins by liposomes incorporating anionic surfactants and ethanol. Int J Pharm. 2006;310(1-2):131-8.

21. Alam MI, Sanjula B, Kanchan K, Javed A, Alka A. Pharmacodynamic evaluation of proniosomal transdermal therapeutic gel containing celecoxib. Sci Asia. 2010;36(4):305-11.

22. Mandawgade SD, Patravale VB. Development of SLNs from natural lipids: Application to topical delivery of tretinoin. Int J Pharm. 2008;36(1-2):132-8.

23. Keat TC, Lai WC, Paul WSH. Characterization of Spreadability of nonaqueous Ethyl cellulose gel matrices using dynamic contact angle. J Pharm Sci. 2008;97(8):3467-82

24. Panchagnula R, Salve PS, Thomas NS, Jain AK, Ramarao P. Transdermal delivery of naloxone: Effect of water, propylene glycol, ethanol and their binary combinations on permeation through rat skin. Int J Pharm. 2001;219(1-2):95105.

25. EL-Samaligy MS, Afifi NN, Mahmoud EA. preparation and experimental design investigation. Int J Pharm. 2006;308(1-2):140-8.

26. Bernsdorff C, Wolff A, Winter R, Gratton E. Effect of hydrostatic pressure on water penetration and rotational dynamics in phospholipid-cholesterol bilayers Biophys J. 1997;72(3):1264-77.

27. [27] Hwang BY, Jung BH, Chung SJ, Lee M, Shim C. In vitro skin permeation of nicotine from proliposomes. J Control Rel. 1997;49:177-184.

28. Fang JY, Hong CT, Chiu WT, Wang YY. Effect of liposomes and niosomes on skin permeation of enoxacin. Int J Pharm. 2001;219(1-2):61-72.

29. Schreier H, Bouwstra J. Liposomes and niosomes as topical drug carriers: Dermal and transdermal drug delivery. J Control Rel.1994;30(1):1-15.

30. Fang JY, Hong CT, Chiu WT, Wang YY. Effect of liposomes and niosomes on skin permeation of enoxacin. Int J Pharm. 2001;219(1-2):61-72.

31. Ogiso T, Niinaka N, Iwaki M. Mechanism for enhancement effect of lipid disperse system on percutaneous absorption. J Pharm Sci. 1996;85(1):57-64.

32. Meranda DP, Blum MR. Pharmacokinetics of acyclovir after intravenous and oral administration. J Antimicrob Chemother. 1983;12(Suppl B)29-37.

Article History: Submission Date : 10-02-2021; Revised Date : 21-04-2021; Acceptance Date : 13-05-2021.

Cite this article: Ashok M, Habibuddin M, Raju J. Provesicular Based Colloidal Carriers for Transdermal Drug Delivery: Formulation Aspects and Bioavailability Enhancement of Acyclovir Proliposomal Gels. Int. J. Pharm. Investigation, 2021;11 (2):195-203. 